\title{
Correlates of Protection against Rotavirus Disease and Immune Response: Need for Further Studies
}

\author{
Tagbo BN* \\ Institute of Child Health, University of Nigeria Teaching Hospital, Enugu State, Nigeria \\ *Corresponding Author: Beckie N Tagbo, Institute of Child Health, University of
} Nigeria Teaching Hospital, Enugu State, Nigeria; Email: tagbobeckie@gmail.com

\section{Editorial}

Volume 2 Issue 1

Received Date: April 06, 2018

Published Date: April 23, 2018

DOI: $10.23880 /$ jes-16000105

\section{Editorial}

Rotavirus is a major cause of severe dehydrating acute gastroenteritis especially in infants and young children $[1,2]$. It is responsible for over 200,000 deaths annually ${ }^{3}$ and this is only this number following introduction of effective rotavirus vaccines and other preventive measures. It is contagious and transmissions in some parts of the world have seasonal peaks [3]. Following the introduction of effective oral vaccines in 2006 and 2008, there has been a significant decline in the disease burden in many parts of the world (dropping from pre vaccination mortality of over 500,000 to just over 200,000 ) [4]. Through a global collaborative advocacy and funding support led by Gavi, many developing countries have introduced the rotavirus vaccine into their routine immunization programmes. However, the vaccines have not been introduced in some countries yet [5]. The two major oral vaccines, Rotarix and Rotateq have been shown in large trials to be highly effective in developed countries $\left(80-90 \%{ }^{6}\right)$ but less effective in developing countries (39-49\%) [6].

\section{Virology}

The rotaviruses belong to the genus Rotaviridae, a double-stranded RNA virus consisting of 11 segments. The Group A rotavirus causes disease in humans. The outer capsid proteins, VP4 and VP7 induce production of neutralizing antibodies. Infection of mature enterocytes of the small intestines results in osmotic and secretory diarrhea [7].

\section{Immune Response- Innate, Humoral, And Cellular Immunity}

Rotavirus infection or vaccination elicits both innate (non-specific) and acquired immune response. Acquired immune response includes humoral and cell mediated immune response. The humoral immune response which is better understood consists of B cell rotavirus specific response resulting in neutralizing antibody production. This includes production of IgG, serum IgA and mucosal IgA. The cellular immune response is less well understood but involves CD4 and CD8 $\mathrm{T}$ cells [8,9]. Generally knowledge of immune protective mechanisms against rotavirus remains incomplete. This knowledge is necessary in rotavirus vaccine development and efficacy trials.

\section{Correlates of Protection}

Initial episodes of disease are usually more severe resulting in increasing levels of protection against subsequent exposures. This observed phenomenon was therefore employed in the development and scheduling of rotavirus vaccinations with 2-3 dose schedules. Protection has also been reported from asymptomatic infections ${ }^{8}$.VP6 IgA neutralizing antibodies in the gut are currently used as correlates of protection ${ }^{8}$. Use of VP7 and VP4 IgG and IgA serum neutralizing antibodies as correlates of protection is under debate and our knowledge incomplete, although this has been better demonstrated in natural infections than in vaccine studies $[9,10]$. 


\section{Journal of Embryology \& Stem Cell Research}

The clinical significance of non-neutralizing RV-specific antibodies remains poorly understood. Cellular RVspecific immune response as a correlate of protection is not well established [8,9]. Innate immune response association with protection also remains to be clearly proven.

\section{Way Forward}

The need for further studies on immune response of humans to both rotavirus infection and rotavirus vaccination is imperative and urgent too. The place of cellular immune response requires further elucidation as well as finding other correlates of protection. Although several hypotheses have been put forward on the reasons for low RV efficacy in developing countries, clearer understanding of humoral and cell-mediated immune responses might help in the formulation of more effective vaccines for use in populations where disease burden is highest and vaccine efficacy is lowest. Experimental as well as human studies are both necessary to answer many questions about mechanism of immune protection, other correlates of protection, T-cell and other responses to rotavirus infection and vaccination.

\section{References}

1. Alam MM, Khurshid A, Shaukat S, Rana MS, Sharif S, et al. (2015) Viral Etiologies of Acute Dehydrating Gastroenteritis in Pakistani Children: Confounding Role of Par echoviruses. Freed EO, ed. Viruses 7(1): 378-393.

2. Lin CL, Chen SC, Liu SY, Chen KT (2014) Disease Caused by Rotavirus Infection. The Open Virology Journal 8: 14-19.
3. Tagbo BN, Mwenda JM, Armah G, Obidike EO, Okafor UH, et al. (2014) Epidemiology of rotavirus diarrhea among children younger than 5 years in Enugu, South East, Nigeria. Pediatr Infect Dis J 33(1): 19-22.

4. Tate JE, Burton AH, Pinto CB, Parashar UD (2016) Global, Regional, and National Estimates of Rotavirus Mortality in Children $<5$ Years of Age, 2000-2013. Clin Infect Dis 62(2): 96-105.

5. Rora Council (2018) Global introduction status.

6. Lopman BA, Pitzer VE, Sarkar R, Gladstone B, Patel M, et al (2012) Understanding Reduced Rotavirus Vaccine Efficacy in Low Socio-Economic Settings. PLOS ONE 7(8).

7. Desselberger U (2017) Differences of Rotavirus Vaccine Effectiveness by Country: Likely Causes and Contributing Factors. Pathogens 6(4): 65.

8. Desselberger U, Huppertz HI (2011) Immune Responses to Rotavirus Infection and Vaccination and Associated Correlates of Protection. The Journal of Infectious Diseases 203(2): 188-195.

9. Angel J, Steele AD, Franco MA (2014) Correlates of protection for rotavirus vaccines: Possible alternative trial endpoints, opportunities, and challenges. Human Vaccines \& Immunotherapeutic 10(12): 3659-3671.

10. Kaufhold RM, Field JA, Caulfield MJ, Heather Joseph, Su Wang, et al. (2005) Memory T-Cell Response to Rotavirus Detected with a Gamma Interferon Enzyme-Linked Immunospot Assay. Journal of Virology 79(9): 5684-5694. 